\title{
Nutrição e manejo do solo em fruteiras de caroço em regiões de clima temperado
}

\section{Nutrition and soil management in stone fruit trees in temperate regions}

\author{
Adamo Domenico Rombolà'; Giovambattista Sorrenti²; \\ Gilmar Arduino Bettio Marodin ${ }^{3 *}$; André Zambam De Pieri ${ }^{4}$; Enrico Barca ${ }^{5}$
}

\begin{abstract}
Resumo
As técnicas adotadas no cultivo das frutas de caroço ou drupáceas devem ser definidas com uma visão de sustentabilidade ecológica e econômica. Tal visão sugere que os aspectos produtivos, voltados ao aumento da qualidade, sejam compatíveis com o ambiente, mantendo e, se possível, aumentando a qualidade dos recursos ambientais e garantindo, ao mesmo tempo, um adequado retorno econômico aos fruticultores. No presente trabalho são discutidos aspectos da fertilização e manejo do solo das drupáceas, assumindo como modelo o pessegueiro, espécie mais estudada, sendo evidenciados alguns resultados obtidos recentemente em outras espécies do grupo, com ênfase na Itália, mas que podem ser aplicados, na maioria dos casos, em qualquer situação.
\end{abstract}

Palavras-chave: Adubação, pessegueiro, ameixeira

\begin{abstract}
The agronomic techniques adopted for stone fruit trees cultivation should be ecologically and economically sustainable. This implies that production processes, apart from improving fruit yield and quality, mantain or increase the value of natural resources, guaranteeng satisfactory incomes to growers. The paper discusses fertilization and soil management aspects for peach, fruit crop largely investigated, and other stone fruit species, with emphasis on the Italian fruit industry.
\end{abstract}

Key words: Fertilization, peach, plum

1 Prof. do Dipartimento di Colture Arboree da Universidade de Bologna, Itália. E-mail: adamo.rombola@unibo.it

2 Pesquisador do Dipartimento di Colture Arboree da Universidade de Bologna, Itália. E-mail: sorrenti@agrsci.unibo.it

3 Prof. Associado III da Faculdade de Agonomia/UFRGS, Bolsista do CNPq. E-mail: marodin@ufrgs.br

4 Eng $^{\circ}$ Agr $^{\circ}$, da AGROSPE Vacaria, RS. E-mail: azdepieri@gmail.com

5 Eng $^{\circ}$ Agr $^{\circ}$, Imola, Itália. E-mail: enrico.barca@gmail.com

* Autor para correspondência 


\section{A adubação na fase de pré-plantio}

Com o objetivo de organizar racionalmente os interventos de fertilização e aspectos de condução do pomar relacionados à irrigação, ao manejo do solo, à escolha de porta-enxerto, espaçamento e outros tratos culturais é necessário efetuar uma meticulosa análise do solo e adequada correção antes da implantação. Deve-se destacar que, nas condições de solo das principais regiões produtoras de frutas de caroço do Brasil é fundamental a realização da calagem, pois ao contrário das regiões mediterrâneas, os solos são ácidos e normalmente requerem elevadas quantidades de calcário.

Um dos principais fatores a considerar na adubação dos pomares são os efeitos da matéria orgânica sobre a fertilidade do solo. Nas principais zonas produtoras de pêssego da área mediterrânea se observa uma contínua diminuição do conteúdo de matéria orgânica, resultando em decréscimo da fertilidade química (ex.: retrogradação de fósforo), física (degradação da estrutura do solo) e biológica (CARNEVALI et al., 2006).

A fertilização orgânica na fase de préimplantação é uma oportunidade única de aumentar o conteúdo de matéria orgânica (MO) na porção de solo explorada pelas raízes. A aplicação de MO é feita antes da aração em quantidades que variam segundo o composto e o tipo de solo. Por exemplo, pode-se distribuir até 80-100 t/ha de esterco bovino compostado no preparo inicial do solo, com o cuidado de fracionar as aplicações nos anos sucessivos, particularmente em terrenos soltos, caracterizados por uma elevada mineralização. Isto para evitar que uma elevada quantidade de nutrientes esteja à disposição da planta nos primeiros anos após a implantação (TOSELLI et al., 2006). Entre os melhores produtos, os compostados mistos, por acessibilidade, custo e qualidade, são preferíveis quando o esterco não é disponível. A partir de experimentos conduzidos com pessegueiro (BALDI et al., 2010) foi observado que o aporte de 10 toneladas de matéria seca/ha/ano de composto misto determina um aumento da M.O. no solo de aproximadamente $1 \%$ no período de 5 anos. A adição de 5 toneladas de ms/ha/ano, ao contrário, determina um incremento mais lento da M.O. (Tabela 1), mas tem a vantagem de não proporcionar a presença de nitratos. Como alternativa aos estercos, podese utilizar um composto misto que apresente maior concentração de matéria seca, de $\mathrm{N}$ e menor relação $\mathrm{C} / \mathrm{N}$, mas frequentemente apresenta maior concentração de metais pesados. Comercialmente existem variados tipos de compostos, por isso é fundamental conhecer sua composição química e biológica.

Tabela 1. Efeito de tratamentos de fertilização sobre a concentração de matéria orgânica (M.O.) do solo de um pomar de pessegueiros adultos cv Stark Red Gold/GF 677 em Ravenna, IT.

\begin{tabular}{lccccc}
\hline \multirow{2}{*}{ Tratamentos } & $1^{\circ}$ ano & $2^{\circ}$ ano & $3^{\circ}$ ano & $4^{\circ}$ ano & $5^{\circ}$ ano \\
\cline { 2 - 5 } & \multicolumn{5}{c}{ Matéria Orgânica (\%) } \\
\hline Controle (sem fertiliz.) & 1,67 & 1,47 & 1,52 & $1,45 \mathrm{c}$ & $1,65 \mathrm{c}$ \\
Mineral & 1,65 & 1,47 & 1,60 & $1,50 \mathrm{c}$ & $1,55 \mathrm{c}$ \\
Composto $5 \mathrm{t} \mathrm{ha}^{-1}$ & 1,62 & 1,52 & 1,92 & $2,07 \mathrm{~b}$ & $1,98 \mathrm{~b}$ \\
Composto $10 \mathrm{t} \mathrm{ha}^{-1}$ & 1,62 & 1,65 & 2,00 & $2,97 \mathrm{a}$ & $2,48 \mathrm{a}$ \\
Significancia & - & $n s$ & $n s$ & $* * *$ & $* * *$ \\
\hline
\end{tabular}

Fonte: Baldi et al. (2010). 
Outros compostos interessantes são constituídos de esterco suíno, eqüino ou ovino, caracterizados por distintas concentrações de nitrogênio $(\mathrm{N})(0,3$ - 0,8\%), anidrido fosfórico $\left(\mathrm{P}_{2} \mathrm{O}_{5}\right)(0,2-0,6 \%)$ e óxido de potássio $\left(\mathrm{K}_{2} \mathrm{O}\right)(0,5-1,7 \%)$. Cama de aviário, com teores de $\mathrm{N}(0,8 \%-3,5 \%), \mathrm{P}_{2} \mathrm{O}_{5}(0,6-$ $2,5 \%), \mathrm{K}_{2} \mathrm{O}(0,6-1,5 \%)$ (valor referido ao produto original) pode ser incluída como boa opção para incrementar a M.O., desde que seja bem compostada, pois enquanto fresca pode ser fitotóxica.

Os compostos orgânicos devem apresentar uma equilibrada relação $\mathrm{C} / \mathrm{N}$ (entre 20 e 30), a fim de adicionar uma boa quantidade de húmus estável e, ao mesmo tempo, de não criar condições de carência de N.

Considerando que os produtos vegetais frescos apresentam uma baixa relação $\mathrm{C} / \mathrm{N}$ e, por isso, baixa capacidade de formar húmus, a utilização de adubo verde (leguminosas) em fase de préimplantação, geralmente se traduz em reduzida adição de matéria orgânica estável, tanto pela rápida mineralização, quanto pelas limitadas adições de matéria seca (cerca de 10 t/ha). Com o objetivo de incrementar as substâncias húmicas, aconselha-se utilizar consórcios entre gramíneas e leguminosas e incorporá-las durante a floração (GIOVANNINI; MERLI; MARANGONI, 2003), destacando-se que, no caso de implantação de pomar de pessegueiro, se deve evitar o trevo ou a alfafa, que possuem efeito alelopático sobre os porta-enxertos francos, limitando seu crescimento.

Eventuais adições de fertilizantes minerais na fase de pré-plantio (a base de fósforo- $\mathrm{P}$ e potássioK) são realizadas somente se a disponibilidade desses nutrientes no solo for inferior aos valores tidos como ótimos para as espécies frutíferas perenes. Nos pomares onde se adota o método de cultivo orgânico, o aumento dos teores dos elementos minerais pode ser feito com fertilizantes permitidos pelas respectivas normativas (a exemplo dos fosfatos e sais de potássio).

Durante a fase inicial do pomar, a assimilação dos minerais por parte das plantas jovens, em condições não limitantes, é determinada pela demanda necessária ao crescimento das partes caducas e perenes e as quantidades líquidas anuais de elementos nutritivos absorvidos são limitadas (Tabela 2). Na prática, se foi efetuada uma boa adubação de base, o desenvolvimento normal das plantas durante a fase de condução pode ser obtido adicionando somente nitrogênio. Uma adequada disponibilidade de fósforo no solo promove um rápido crescimento das plantas (ROMBOLÀ et al., 2000a).

Tabela 2. Absorção líquida anual de elementos minerais na fase inicial de um pomar de pessegueiros (cv Springcrest/ GF677; $416 \mathrm{pl} \mathrm{ha}^{-1}$ ), conduzido em vaso atrasado.

\begin{tabular}{lccc}
\hline & \multicolumn{3}{c}{ Absorção líquida anual (g.planta $^{-1}$ ) } \\
\cline { 2 - 4 } & Elemento mineral & \multicolumn{3}{c}{ Ano depois da implantação } \\
\cline { 2 - 4 } & $\mathrm{I}$ & $\mathrm{II}$ & $\mathrm{III}$ \\
\hline $\mathrm{N}$ & 5,1 & 67,2 & 186,9 \\
$\mathrm{P}$ & 0,3 & 3,2 & 11,7 \\
$\mathrm{~K}$ & 3,9 & 55,9 & 151,0 \\
$\mathrm{Ca}$ & 7,8 & 104,9 & 245,8 \\
$\mathrm{Mg}$ & 0,9 & 13,0 & 33,3 \\
\hline
\end{tabular}

Fonte: Modificado de Xiloyannis, Celano e Nuzzo (2006). 
Importantes diferenças nas exigências nutricionais das plantas são ligadas às formas de condução; assim, as formas que permitem elevada densidade de plantio (Y-transversal) possuem demanda mais baixa de minerais a respeito daquelas de baixa densidade (vaso); isto quando se refere individualmente a uma planta, existindo uma demanda mais alta quando se refere à unidade de área. Assim, a maior densidade de plantas em pomares conduzidos em Y-transversal faz com que esse apresente cerca do dobro das exigências nutricionais por hectare, em comparação ao vaso (XILOYANNIS; CELANO; NUZZO, 2006).

A demanda de $K$ na fase de formação das plantas, caracterizada pela ausência (ou limitada presença) de frutos, é moderada. Este fato pode ser explicado devido à quantidade total de $\mathrm{K}$ absorvida pelas plantas jovens ser depositada nas folhas que, quando caem ao solo, liberam a maior parte do $\mathrm{K}$ nos primeiros meses de decomposição, assim como ocorre com o magnésio (TAGLIAVINI et al., 2007).

\section{Adubação na fase produtiva}

As exigências nutricionais das espécies frutíferas em plena capacidade produtiva variam fortemente em função da espécie e do porta-enxerto adotado, aumentado sensivelmente em função do volume de produção. Nessa fase, as exportações de nutrientes são determinadas pelo crescimento dos órgãos perenes, pela madeira de poda, pelas folhas caídas e pelos frutos (Tabelas 3 e 4). Porém, enquanto o incremento anual de biomassa dos órgãos permanentes é modesto, as partes caducas elou o material exportado com a poda e, principalmente, pela produção podem constituir quantidades consideráveis.

Tabela 3. Exportação de elementos minerais em pessegueiro ao $5^{\circ}$ ano após o plantio (cv Springcrest; Y-transversal; $1111 \mathrm{pl} \mathrm{ha}^{-1}$; produção $\left.21 \mathrm{t} \mathrm{ha}^{-1}\right)$.

\begin{tabular}{lcccccc}
\hline & M.S. & $\mathrm{N}$ & $\mathrm{P}$ & $\mathrm{K}$ & $\mathrm{Ca}$ & $\mathrm{Mg}$ \\
\cline { 2 - 7 }$\left(\mathrm{kg} \mathrm{planta}^{-1}\right)$ & & \multicolumn{5}{c}{$\left(\mathrm{g} \mathrm{planta}^{-1}\right)$} \\
Produção & 2,1 & 20 & 2 & 11 & 1 & 1 \\
Poda verde & 2,1 & 51 & 4 & 35 & 48 & 8 \\
Poda seca & 2,0 & 25 & 2 & 8 & 35 & 2 \\
Folhas caídas & 2,6 & 61 & 5 & 54 & 72 & 14 \\
TOTAL & 8,8 & 157 & 12 & 108 & 156 & 25 \\
\hline
\end{tabular}

Fonte: Xiloyannis, Celano e Nuzzo (2006).

Tabela 4. Quantidade de elementos nutritivos exportados de um pomar de ameixeiras européias em plena produção.

\begin{tabular}{lcccccc}
\hline \multirow{2}{*}{ Órgão } & M.S. & $\mathrm{N}$ & $\mathrm{P}$ & $\mathrm{K}$ & $\mathrm{Ca}$ & $\mathrm{Mg}$ \\
\cline { 3 - 7 } & $\left(\mathrm{t} \mathrm{ha}^{-1}\right)$ & & & $\left(\mathrm{kg} \mathrm{ha}^{-1}\right)$ & & \\
\hline Frutos $^{1}$ & 3,5 & $17,1-54,2$ & 0,4 & 45,5 & 1,2 & 2,1 \\
Folhas $^{2}$ & 3,0 & 58,2 & 3,3 & 39,0 & 52,1 & 7,5 \\
Madeira de poda $^{\text {Poda verde }}$ & 3,2 & 36,4 & 4,5 & 19,8 & 40,3 & 7,0 \\
TOTAL & 0,2 & 4,9 & 0,5 & 7,7 & 1,6 & 0,8 \\
\hline
\end{tabular}

Fonte: Toselli et al. (2006); ${ }^{1}$ Plich e Wojcik (2002), ${ }^{2}$ Alcaraz-Lopez, Botia e Alcaraz (2003). 


\section{A adubação nitrogenada}

O N é o elemento nutritivo de maior importância na fertilização das drupáceas. Excessos de $\mathrm{N}$ retardam a maturação, reduzem a coloração e alteram os parâmetros qualitativos (DAY et al., 1999). A disponibilidade de $\mathrm{N}$ apresenta uma série de implicações na relação entre hospedeiropatógenos e/ou parasitas: sabe-se que excessos de $\mathrm{N}$ estimulam o crescimento vegetativo, atrasam a lignificação dos ramos e expõem a planta a ataques parasitários. Todavia, foi observado que carências de $\mathrm{N}$ tornam o pessegueiro mais sensível aos cancros provocados por infecções de Pseudomonas syringae (CAO et al., 2005). O aumento da disponibilidade de $\mathrm{N}$ nítrico no terreno determina, no pessegueiro, um aumento na produção de ápices radicais, mas, ao mesmo tempo, uma diminuição da superfície radical total (BALDI, 2006). A sua dinâmica no terreno é complexa, podendo estar presente em várias formas. A forma mais consistente delas é a orgânica, que por obra da flora bacteriana é mineralizada, tomando a forma do íon amônio $\left(\mathrm{NH}_{4}^{+}\right)$e sucessivamente do íon nitrato $\left(\mathrm{NO}_{3}^{-}\right)$. $\mathrm{O} \mathrm{N}$ nítrico não é retido pelos colóides do solo e é facilmente lixiviado. Isso torna esse nutriente mais difícil de ser manejado na realização dos planejamentos de fertilização, em comparação aos outros minerais.

$\mathrm{Na}$ escolha da forma nitrogenada a ser empregada é oportuno considerar, entre muitos fatores, o efeito sobre a fisiologia da planta. De fato, em outras frutíferas foi observado que a diferente disponibilidade de nitrogênio (nítrico ou amoniacal) no solo pode influenciar a fertilidade dos órgãos reprodutivos, geralmente favorecida pela presença de nitrogênio amoniacal (GAO; MOTOSUGI; SUGIURA, 1992), assim como a produtividade das plantas (ZAPPIA et al., 2006). Todavia, o uso repetido de fertilização amoniacal em fruticultura irrigada pode provocar um empobrecimento a médio período (3-5 anos) das bases de troca ( $\mathrm{Ca}$, $\mathrm{Mg}, \mathrm{K}$ ), sob o gotejador (NEILSEN; HOYT; NEILSEN, 1995). Na maioria dos solos a concentração de nitrogênio nítrico é muito maior em relação aos amoniacais devido ao rápido processo de nitrificação. Apesar do nitrogênio nítrico ser considerado a maior fonte de $\mathrm{N}$ para a nutrição, é possível afirmar que nas drupáceas, assim como em outras espécies arbóreas, a importância do nitrogênio amoniacal é subestimada. De fato, em plantas utilizadas como modelos foi observado que a velocidade de absorção do $\mathrm{NH}_{4}^{+}$é superior ou, pelo menos, similar à do $\mathrm{NO}_{3}^{-}$. Sabe-se que em presença de $\mathrm{NH}_{4}^{+}$há uma inibição da absorção de $\mathrm{NO}_{3}^{-}$. É interessante observar que de um ponto de vista aplicativo, as relações entre $\mathrm{NH}_{4}^{+} \mathrm{e} \mathrm{NO}_{3}^{-}$no solo poderiam ser modificadas a favor do primeiro com o uso de inibidores de nitrificação, sintéticos (ex. DMPP) (TAGLIAVINI et al., 1995) ou naturais (ex. da pasta de nim), fato que contribuiria a reduzir as perdas de $\mathrm{NO}_{3}^{-}$(KIRAN; PATRA, 2003).

O pessegueiro é capaz de utilizar, na primavera, quantidades consideráveis de reservas nitrogenadas, acumuladas nos órgãos perenes (particularmente nas raízes), nos anos precedentes (MUÑOZ et al., 1993; QUARTIERI et al., 1999). No início da fase do "endurecimento do caroço" quase 50\% do nitrogênio contido nos órgãos recém formados (ramos do ano e frutos) provém do ciclo interno da planta (nitrogênio que é remobilizado no início da primavera), ao contrário, o nitrogênio absorvido pelas raízes assume uma importância relevante somente nas fases fenológicas sucessivas. Uma boa disponibilidade de $\mathrm{N}$ durante a primavera estimula o crescimento de maior número de brotações, que se desenvolvem a partir da abertura de gemas latentes (LOBIT et al., 2001).

No verão, durante a máxima atividade vegetativa, as folhas acumulam $\mathrm{N}$ até pouco antes da sua queda, quando o $\mathrm{N}$ migra das folhas para as raízes, ao caule e aos ramos mais velhos, gerando o acúmulo de substâncias nitrogenadas de reserva. O nitrogênio exportado por um pomar de pessegueiros é determinado pela sua idade, pelo seu desenvolvimento vegetativo e pelas técnicas adotadas: combinação de enxerto/porta-enxerto, densidade de plantio, forma de condução, poda e irrigação (TAGLIAVINI et al., 1995). 
Os critérios que devem ser adotados para o manejo da adubação nitrogenada de um pomar de pessegueiros foram descritos em trabalhos precedentes (ROMBOLÀ et al., 2000b). Por exemplo, para pomares da Região da EmiliaRomagna (Itália) se recomenda fracionar as aplicações de $\mathrm{N}$ nas seguintes fases:

1. Queda de pétalas, $25-30 \%$ do total; 2. raleio dos frutos, cerca de $40-50 \%$ e 3 . em pós-colheita, cerca de $20-25 \%$.
Do ponto de vista prático, todavia, é preferível não aplicar nitrogênio na forma mineral antes da fase fenológica de "queda de sépalas", pois aplicações precoces são pouco eficientes e podem ser lavadas por chuvas primaveris. Tais indicações variam em função do ambiente pedoclimático (ex. temperatura do solo), da dinâmica de crescimento radical, do porta-enxerto e da cultivar. Aplicações em póscolheita apresentam-se eficazes para incrementar as substâncias nitrogenadas de reserva da planta (Tabela 5 - ROMBOLÀ et al., 1997).

Tabela 5. Efeito da adubação nitrogenada em pós-colheita sobre a concentração de N (\% m.s.) nos órgãos perenes de pessegueiro (cv. Elegant Lady / PS B2).

\begin{tabular}{|c|c|c|c|c|c|c|}
\hline \multirow{2}{*}{ Tratamentos } & \multicolumn{3}{|c|}{$1^{\circ}$ ano } & \multicolumn{3}{|c|}{$2^{\circ}$ ano } \\
\hline & Ramos & Raízes & Gemas & Ramos & Raízes & Gemas \\
\hline Controle & 1,08 & $1,40 \mathrm{~b}$ & 2,14 & $1,03 \mathrm{~b}$ & $0,98 \mathrm{~b}$ & 1,89 \\
\hline Nitrato de amônio (solo) & 1,22 & $1,56 \mathrm{ab}$ & 2,30 & $1,17 \mathrm{ab}$ & $1,14 \mathrm{ab}$ & 2,03 \\
\hline Uréia foliar (3\%) & 1,09 & $1,54 \mathrm{ab}$ & 2,18 & $1,12 \mathrm{ab}$ & $1,08 \mathrm{ab}$ & 1,91 \\
\hline $\begin{array}{l}\text { Fertilizante } \mathrm{N} \text { adicionado com } \\
\text { DCD (solo) }\end{array}$ & 1,17 & $1,70 \mathrm{a}$ & 2,17 & $1,26 \mathrm{a}$ & $1,21 \mathrm{a}$ & 1,98 \\
\hline $\begin{array}{l}\text { Fertilizante } \mathrm{N} \text { adicionado com } \\
\text { IBDU (solo) }\end{array}$ & 1,21 & $1,63 \mathrm{a}$ & 2,21 & $1,24 \mathrm{a}$ & $1,27 \mathrm{a}$ & 2,05 \\
\hline
\end{tabular}

Fonte: Rombolá et al. (1997).

Considera-se importante destacar que a adubação tardia com nitrogênio pode se apresentar particularmente útil quando se opera: (a) em anos com elevada carga produtiva, (b) em terrenos com baixo teor de $\mathrm{N}$ mineral e (c) depois de um verão muito chuvoso, que pode ter favorecido a lixiviação do nitrogênio presente. Para fazer com que o nitrogênio distribuído seja efetivamente direcionado aos órgãos "alvo" (ramos e gemas, em particular) é oportuno intervir até setembro com aplicações de $25-30 \mathrm{~kg} \mathrm{ha}^{-1}$ de $\mathrm{N}$ e reduzir a $10-$ $15 \mathrm{~kg} \mathrm{ha}^{-1}$, caso se utilize a fertirrigação (TOSELLI; TITTARELLI; MARANGONI, 1999). Aplicações feitas tardiamente no outono devem ser evitadas pela sua baixa eficiência e porque aumentam a quantidade de nitratos potencialmente lixiviáveis durante os meses de inverno. Pelas mesmas razões, aplicações tardias com adubos nitrogenados de liberação lenta não são aconselhadas (ROMBOLÀ et al., 1997).

Como as doses não podem ser estabelecidas com antecedência, por causa das diversas condições pedoclimáticas e de fertilidade natural, é importante utilizar um modo objetivo para quantificar as aplicações de N. A metodologia mais difusa, aplicada em larga escala em pessegueiros (SCUDELLARI et al., 1998a), prevê a determinação do nitrogênio mineral no solo ou na solução antes de uma adubação e o cálculo da quantidade de nitrogênio mineral disponível por hectare, a fim de estimar a quantidade para reposição (TAGLIAVINI et al., 1995). A indicação sobre doses de $\mathrm{N}$ a aplicar, resulta da diferença entre a quantidade de nitrogênio necessária em um determinado período e a disponibilidade de nitrogênio no solo. 
Nos pomares dotados de fertirrigação, devido à notável eficiência do sistema, é possível reduzir 30-50\% das aplicações unitárias de fertilizante nitrogenado (ZAVALLONI et al., 1998; AMADEI et al., 2006).

Os benefícios da aplicação de nitrogênio através da fertirrigação (antecipação da fase produtiva, menores perdas por lixiviação) são mais evidentes em plantas jovens, onde o sistema radicular é pouco desenvolvido e localizado abaixo da linha de gotejo (ROMBOLÀ et al., 2000a). Mesmo em plantas adultas a eficácia da aplicação de $\mathrm{N}$ em fertirrigação é freqüentemente comparável a da fertilização convencional (MALAGUTI et al., 2006).

A fertirrigação oferece a possibilidade de conjugar aspectos produtivos e ambientais, porém esta técnica requer um manejo racional da água de maneira que se evitem carências hídricas que provocam o aumento da salinidade da solução do solo e lixiviações de nitrogênio e outros nutrientes ou fertilizantes (a ex. quelatos de ferro) com elevada mobilidade ao longo do perfil do solo e que provocam um importante impacto ambiental (MALAGUTI et al., 2006).

Os fertilizantes nitrogenados disponíveis no sistema de produção biológica são geralmente orgânicos, consequentemente o $\mathrm{N}$ não é prontamente disponível para a planta, mas sim, somente após a mineralização. Por esse motivo a época de adubação e a de absorção por parte das raízes não coincidem, sendo geralmente distantes entre si. Os vários fertilizantes podem desta forma, ser classificados com base em sua velocidade de mineralização. Para superar eventuais condições de carência de N, podese empregar fertilizantes orgânicos com elevados teores de $\mathrm{N}$ e rápida mineralização, a exemplo de sangue seco de animais, disponível comercialmente na Europa (SORRENTI et al., 2008b).

\section{A adubação com os demais macroelementos}

A dinâmica do $\mathrm{P}$ e do $\mathrm{K}$ no solo é menos complexa em relação à do $\mathrm{N}$ e isso torna mais ágil a técnica de fertilização, sobretudo considerando que ambos os elementos são fixados pelos colóides, principalmente o $\mathrm{P}$, sendo que esse é menos suscetível à lixiviação em relação ao $\mathrm{K}$. A baixa disponibilidade de $\mathrm{P}$, fenômeno observado tanto em solos com reação ácida como em solos alcalinos, pode limitar sensivelmente a atividade vegetativa (TAGLIAVINI et al., 2000a). Todavia, o $P$ é exportado anualmente em pequenas quantidades que raramente superam $20 \mathrm{~kg} \mathrm{ha}^{-1}$. Além disso, a determinação analítica do $\mathrm{P}$ fornece uma boa indicação sobre a fração assimilável pelas raízes, por isso a análise do solo pode ser utilizada para orientar a adubação. Com base nessas considerações, no caso de níveis adequados de P no solo (12-16 $\mathrm{mg} \mathrm{kg}^{-1}$, método Olsen), uma fertilização fosfatada a cada 3-4 anos com cerca de 40-50 kg P ha-1 é suficiente para compensar as exportações. Devese recordar que a biodisponibilidade do fósforo pode ser sensivelmente incrementada com a adição de fertilizantes orgânicos, enquanto que, em solos ácidos ocorre uma contribuição importante das micorrizas para a absorção do P.

No plano de fertirrigação, a aplicação de P é feita nas primeiras fases de desenvolvimento vegetativo, visto que esse elemento estimula o desenvolvimento radical em condições de baixas temperaturas do solo (TAGLIAVINI et al., 2000b).

$\mathrm{O} \mathrm{K}$ é o elemento mineral mais abundante nos frutos (Tabela 6) o qual, quando disponível, proporciona um bom tamanho, adequado equilíbrio ácidos/açúcares e uma intensa coloração da epiderme. Estes importantes aspectos positivos não devem ser superestimados, pois o excesso de potássio reduz fortemente a conservabilidade dos frutos. Experimentos conduzidos em diversas espécies arbóreas evidenciaram as vantagens da fertirrigação sobre a nutrição potássica. Tal técnica é particularmente indicada em solos argilosos nos quais o $\mathrm{K}$ se move pouco ao longo do perfil (MALAGUTI et al., 2006). A nutrição potássica é também melhorada somente pela irrigação, devido ao incremento da mobilidade deste elemento no 
solo e a um possível efeito fisiológico sobre a planta (maior carga de K no xilema). Visto que a cobertura vegetal é capaz de acumular em sua parte aérea, elevadas quantidades de potássio (uma cobertura de gramíneas com $15 \mathrm{~cm}$ de altura contém até 90 $\mathrm{kg} \mathrm{ha}^{-1}$ de K), em terrenos com baixa quantidade de
$\mathrm{K}$ as roçadas devem ser mais freqüentes, sobretudo quando a demanda de $\mathrm{K}$ das plantas é muito elevada (durante o engrossamento dos frutos). Deve-se destacar que uma excessiva disponibilidade de K no terreno, também pode causar efeitos de competição com conseqüente redução da absorção de cálcio (Ca) e magnésio (Mg) (TAGLIAVINI et al., 2000b).

Tabela 6. Quantidade de macro e de microelementos exportados pelos frutos de pêssego, ameixa, cereja e damasco a cada tonelada de produção.

\begin{tabular}{lcccc}
\hline \multirow{2}{*}{ Macroelementos } & \multicolumn{4}{c}{ Quantidades exportadas $\left(\mathrm{kg} \mathrm{t}^{-1}\right)$} \\
\cline { 2 - 5 } & Pêssego & Ameixa & Cereja & Damasco \\
\hline Nitrogênio & $0,90-1,00$ & 0,49 & $2,00-2,35$ & 0,87 \\
Fósforo & 0,25 & 0,10 & $0,18-0,20$ & 0,19 \\
Potássio & 2,00 & 1,72 & $1,48-1,70$ & 2,96 \\
Magnésio & 0,10 & 0,07 & $0,10-0,16$ & 0,08 \\
Cálcio & 0,05 & 0,04 & $0,11-0,16$ & 0,14 \\
Microelementos & & Quantidades exportadas $\left(\mathrm{g} \mathrm{t}^{-1}\right)$ & 5,40 \\
$\quad$ Ferro & 1,10 & 1,00 & $5,63-10,77$ & 0,79 \\
\multicolumn{1}{c}{ Manganês } & 0,47 & 0,49 & $0,70-0,97$ & 2,60 \\
\hline
\end{tabular}

$\mathrm{P}_{2} \mathrm{O}_{5}=\mathrm{P} \times 2,29 ; \mathrm{K}_{2} \mathrm{O}=\mathrm{K} \times 1,2 ; \mathrm{MgO}=1,65 ; \mathrm{CaO}=1,4$

Fonte: Tagliavini et al. (2000b).

As exigências de $\mathrm{Mg}$ das frutíferas são limitadas. Condições de carência de $\mathrm{Mg}$ podem ocorrer em solos muito soltos ou com $\mathrm{pH}$ sub-ácido, nos quais o Mg pode ser lixiviado. Nessas condições, assim como nos casos de elevadas concentrações de K, que limitam a absorção radical de $\mathrm{Mg}$, esse elemento pode ser aplicado tanto ao solo quanto na copa.

Para a adição de $\mathrm{K}, \mathrm{Mg}$ e $\mathrm{P}$ pode-se aplicar a norma que prevê restituir anualmente as quantidades exportadas pela produção (Tabelas 3 e 4), fazendo eventuais correções às características básicas do solo.

O Ca é um elemento que desenvolve um papel importante ao conferir consistência à polpa. Tendo em vista que o $\mathrm{Ca}$ se move prevalentemente pelo xilema, através do fluxo transpiratório, a concentração de Ca no fruto varia sensivelmente de acordo com sua posição no interior da copa; frutos expostos à luz apresentam uma concentração de Ca maior em relação aqueles sombreados. Para favorecer a absorção de $\mathrm{Ca}$ e a sua distribuição para os frutos é oportuno realizar uma série de práticas agronômicas, como por exemplo, assegurar uma boa aeração do solo, uma adequada disponibilidade hídrica e alcançar o equilíbrio vegeto-produtivo das plantas.

Mesmo que os solos da área mediterrânea sejam bem dotados de $\mathrm{Ca}$, se recorre frequentemente às adubações foliares com o objetivo de aumentar a concentração desse elemento no fruto, mas o êxito varia em função da espécie e da época de aplicação. Em nectarineiras as aplicações foliares de cálcio são efetuadas com o intuito de reduzir o aparecimento de microlesões sobre a casca que, além de causar o aparecimento de rugosidade, podem se tornar pontos de inóculo de podridão parda (Monilinia $s p p$ ). Os efeitos dos tratamentos com cálcio estão ainda sob discussão, pois, exceto alguns resultados 
promissores nas cultivares de nectarineiras Caldesi 2000, Stark Redgold e Venus, foram registrados efeitos negativos tanto em relação ao controle da rugosidade como em relação à incidência de podridões (SCUDELLARI et al., 1998b). Todavia, os vários experimentos evidenciaram que a eficácia dos formulados a base de cloreto de $\mathrm{Ca}$ é similar àquela dos complexados orgânicos de $\mathrm{Ca}$ mais caros (SOTIROPOULOS; THEORIOS.; VOULGARAKIS, 2010).

Recentemente maior atenção tem sido dada ao uso de extratos vegetais. Dados obtidos em experimentos em vaso indicam que a aplicação de extratos vegetais líquidos obtidos a partir da maceração de folhas e colmos de algumas espécies herbáceas (ex. Urtica dioica, Amaranthus retroflexus) podem melhorar o crescimento e a nutrição de pessegueiros. Em particular, extratos de Amaranthus retroflexus podem fornecer quelatos naturais de $\mathrm{Fe}$, os quais são importantes transportadores deFe(MATOCHA;PENNINGTON, 1982), representando uma promissora prática alternativa para controlar a clorose férrica, comum nos solos calcáreos (ROMBOLÀ et al., 2002; SORRENTI et al., 2009). Isso sugere que, além de outros fatores (composição mineral, componentes quelantes naturais), as mudanças morfo-fisiológicas observadas nas plantas tratadas são parcialmente devidas a substâncias biorreguladoras presentes nos extratos.

\section{O manejo do solo}

A forma de manejar o solo exerce uma forte influência sobre a fertilidade do mesmo e sobre a nutrição mineral (ROVERSI; MONTEFORTE, 2003). A biomassa produzida pela cobertura vegetal varia em função das condições pedoclimáticas e das espécies que a compõem. A biomassa sofre processos de decomposição sucessivos por obra da microflora do solo até a completa mineralização, e os elementos que se tornam disponíveis são reciclados no solo e contribuem positivamente para o balanço nutricional do pomar. A dinâmica pela qual os nutrientes contidos na cobertura vegetal são liberados no solo é pouco conhecida. Tagliavini et al. (2007) estimaram que uma cobertura vegetal com Lolium perenne libera ao solo, durante as primeiras 8 semanas depois de uma roçada, $50 \%$ do $\mathrm{N}$ contido inicialmente.

A cobertura vegetal também melhora a disponibilidade dos elementos minerais pouco móveis nas camadas mais profundas do solo. Exemplificando, o sistema radicular das plantas de cobertura é capaz de transferir $\mathrm{P}$ e $\mathrm{K}$ em profundidade, graças à produção de excreções orgânicas e à cíclica renovação das raízes. Em muitos pomares manejados com cobertura vegetal foi observado um aumento do conteúdo destes dois elementos nas folhas. O tremoço branco (Lupinus albus L.) é capaz de solubilizar o fósforo a partir de complexos insolúveis Ca-P, mediante a secreção na rizosfera de ácidos orgânicos (principalmente ácido cítrico), ao contrário, o cece (Cicer arietinum L.) assegura a mobilização do P sob forma orgânica, através da secreção de elevadas quantidades de fitases e fosfatases ácidas (CESCO; ROMBOLÀ, 2007).

A utilização de cobertura do pomar com gramíneas é capaz de liberar ao solo fitosideróforos (quelantes naturais), determinando um aumento da disponibilidade do ferro e de outros micronutrientes a favor das espécies arbóreas (ROMBOLÀ et al., 2003), cumprindo uma função similar àquela que as leguminosas realizam com o nitrogênio.

Em condições de campo a escolha das espécies a empregar na cobertura do solo deve considerar diversos fatores como: disponibilidade de água, temperatura, estrutura do solo, compatibilidade com a espécie frutífera, capacidade das gramíneas de tolerar condições de sombreamento dos pomares e a propensão a excretar fitosideróforos na rizosfera. Para limitar eventuais fenômenos de competição por parte da cobertura vegetal é oportuno utilizar espécies de gramíneas com lento crescimento e com 
baixa exigência hídrica, assim como estabelecer adequadas técnicas de gestão da cobertura vegetal (ex. freqüência de roçadas).

Em ambientes com boa precipitação e chuvas regularmente distribuídas ao longo do ano, a cobertura vegetal pode ser utilizada também na linha de plantio (MARANGONI; QUARTIERI; SCUDELLARI, 1998). Porém, a fim de evitar competições nutricionais, pode ser necessário, durante a fase de estabelecimento da cobertura do solo, incrementar as aplicações de fertilizantes previstas para o pomar. No caso de porta-enxertos muito vigorosos (a exemplo do GF677 para pessegueiros) a adoção da técnica de cobertura de solo pode contribuir para conter o excessivo vigor da copa (GIOVANNINI; MERLI; MARANGONI, 2003).

Durante a fase de condução do pomar, quando os recursos hídricos não são limitantes, a cobertura do solo com espécies de gramíneas ou o consórcio gramínea/leguminosa é fundamental para incrementar o conteúdo de matéria orgânica e o nível de biodiversidade no solo. Além disso, cria condições ideais para que a elevada quantidade de resíduos vegetais (folhas e madeira de poda), produzidos na sucessiva fase de maturação, possa ser rapidamente decomposta e reciclada no solo.

Estudos recentes demonstraram que o uso de solo descoberto mediante a aplicação de produtos à base de glifosato pode inibir o crescimento vegetativo, a absorção dos nutrientes e aumentar a suscetibilidade das plantas aos patógenos. O glifosato, de fato, pode ser facilmente translocado da parte aérea às raízes das plantas tratadas, depois ser liberado na rizosfera e sucessivamente absorvido pelas plantas arbóreas (NEUMANN et al., 2006).

\section{A adubação foliar}

A capacidade das plantas em absorver rapidamente tanto macro como micronutrientes permite intervir com sucesso quando condições desfavoráveis no solo impedem a absorção radicular dos nutrientes (ex. terrenos frios ou sem aeração). Todavia, essa técnica apresenta algumas desvantagens em comparação à adubação no solo: 1. o efeito benéfico das aplicações na copa são menos duradouros; 2. muitos formulados encontram dificuldade em penetrar na cutícula foliar; 3. alguns elementos minerais têm uma limitada capacidade de serem translocados para fora da folha, como no caso do Ca (MARSCHNER, 1995), do Zn (ZHANG; BROWN, 1999) ou do Fe complexado com DTPA; 4. a adição do nutriente é limitada (concentrações não superiores a $1 \%$ ) para não ocorrerem queimaduras e necroses foliares.

Estas contra-indicações limitam o uso da adubação foliar na fruticultura, atribuindo-a um papel complementar em relação à fertilização do solo. Esta técnica encontra maior aplicação na distribuição de micronutrientes, que são sujeitos a fenômenos de insolubilização no solo. Em virtude do baixo impacto ambiental e também do baixo custo, a fertilização por via foliar pode representar uma válida alternativa para aplicações "tardias" de $\mathrm{N}$ ao solo (ROMBOLÀ et al., 1997; QUARTIERI et al., 1999). Estudos conduzidos com N marcado demonstram como as folhas senescentes de pessegueiro (fim do verão-início do outono) são muito eficientes em absorver o nitrogênio interceptado. A eficiência de absorção foliar do $\mathrm{N}$ foi experimentalmente medida com o isótopo estável $\mathrm{N}^{15}$ e apresentou variação de 50\% (ROSECRANCE; JOHNSON; WEINBAUM, 1998) a 70\% (TAGLIAVINI et al., 1998), resultando, assim, maior absorção em comparação à adubação ao solo (WEINBAUM; BROWN; JOHNSON, 2002). A absorção de N amídico por parte das folhas de pessegueiro é mais rápida e atinge um pico depois de 48-72 horas após a aplicação e se completa dentro de alguns dias (FURUYA; UMEMIYA, 2002; ROSECRANCE; JOHNSON; WEINBAUM, 1998).

Se a fertilização de pós-colheita é feita precocemente, cerca de $60 \%$ do $\mathrm{N}$ absorvido é repartido com órgãos de reserva (sobretudo às 
raízes). O percentual é reduzido para menos de 50\% se a adubação foliar foi realizada feita pouco antes da queda das folhas, quando os órgãos de reserva são constituídos preferencialmente por ramos de um ano (ROSECRANCE; JOHNSON; WEINBAUM, 1998). Em grande parte da estação vegeto-produtiva a folha de pessegueiro tolera uma concentração de fertilizante nitrogenado foliar de 0,5-1\%, porém, quando a estação está no fim, as folhas maduras aumentam sua tolerância à fitotoxicidade e é possível aumentar consideravelmente a concentração dos nutrientes (JOHNSON et al., 2001). Eventuais queimaduras são toleradas em uma fase que precede por pouco a natural queda das folhas (JOHNSON; AMDRIS, 2001). De qualquer maneira, no caso de utilização de ureia, esta não deve conter biureto. A aplicação de $\mathrm{N}$ via foliar pode encontrar justificativa no período primaveril, sobretudo se as condições ambientais não são favoráveis (ex. baixa temperatura do ar) e se o solo estiver excessivamente úmido. A aplicação foliar de $\mathrm{N}$ prontamente disponível pode melhorar a frutificação, especialmente nas plantas que ainda não estão em plena produção e que não possuem órgãos lenhosos capazes de garantir consistentes reservas.

Entre os formulados nitrogenados a ureia é sem dúvida preferível pelo seu baixo custo, alto teor de $\mathrm{N}$, alta solubilidade encontrada em uma ampla faixa de $\mathrm{pH}$ e, sobretudo, pela sua natureza química apolar que proporciona uma boa afinidade com as ceras da cutícula, as quais solubiliza e atinge mais facilmente o mesófilo foliar, onde inicia realmente a absorção. Experiências conduzidas em pessegueiros demonstram que a gestão da fertilização mediante o uso exclusivo de aplicações foliares é de difícil realização. A partir do confronto de diversas estratégias de adubação se observou que o desenvolvimento dos frutos de pessegueiro melhora quando pelo menos uma parte de $\mathrm{N}$ é aplicada ao solo, favorecendo também o desenvolvimento radicular e a síntese de fitorreguladores endógenos (JOHNSON et al., 2001). Todavia, a parcial aplicação de $\mathrm{N}$ via foliar apresenta a vantagem de limitar o desenvolvimento dos ramos do ano que, em cultivares precoces, pode ser excessivo.

A carência de zinco $(\mathrm{Zn})$ pode ser controlada mediante aplicações foliares feitas na primavera com produtos à base de quelatos ou sulfatos. Experimentos com adubação foliar no outono efetuados em pessegueiros (SANCHEZ; WEINBAUM; JOHNSON, 2006) demonstraram que a fração de $\mathrm{Zn}$ absorvida pelas folhas e translocada aos órgãos perenes das plantas é baixa (7\%), porém ao início do ciclo vegetativo o $\mathrm{Zn}$ armazenado nos órgãos perenes é intensamente mobilizado às novas brotações. Com o objetivo de aumentar a quantidade de $\mathrm{Zn}$ acumulado na planta, alguns autores (JOHNSON; URIU, 1989) recomendam pulverizar as plantas no outono com elevadas doses (11-17 $\left.\mathrm{kg} \mathrm{ha}^{-1}\right)$ de sulfato de zinco $\left(\mathrm{ZnSO}_{4}\right)$.

Uma adequada concentração de boro (B) nas gemas férteis favorece a frutificação em quase todas as drupáceas, inclusive no pessegueiro (SHU et al., 1994), cerejeira (USENIK; STAMPAR, 2002), ameixeira e amendoeira. Da bibliografia internacional se obtém informações sobre o efeito positivo do B sobre a viabilidade do pólen, a fertilidade das anteras, a vitalidade dos grãos de pólen, a divisão celular e a síntese de ácido nucleico nos frutinhos durante a citocinese (MARSCHNER, 1995). As estratégias de adubação incluem aplicações foliares de B logo antes da queda das folhas, a fim de incrementar a presença de B nas gemas férteis e obter um efeito benéfico sobre a frutificação do ano sucessivo ao tratamento. Esta resposta é possível graças à mobilidade floemática do B (BROWN; HU; ROBERTS, 1999), característica das espécies rosáceas, que sintetizam carboidratos alcoólicos (como o sorbitol). Desta maneira, o B das folhas senescentes é acumulado nos órgãos lenhosos e rapidamente mobilizado para as gemas férteis no momento de sua abertura. Mesmo que as adubações foliares de B realizadas no outono sejam, às vezes, mais eficazes que as primaveris (CALLAN et al., 1978), com freqüência 
se faz um ou dois tratamentos próximos da floração, sobretudo se o andamento da estação vegetativa não é favorável. É importante usar doses de B limitadas, pois a faixa entre a condição de carência a excesso é estreita podendo causar sintomas de toxicidade.

O interesse pelo emprego do silício ( $\mathrm{Si}$ ) tem crescido na fruticultura, pois mesmo não sendo considerado um nutriente essencial, é capaz de aumentar a resistência das plantas a patógenos (ex. oídio) e a insetos, além de limitar os estresses abióticos (ex. estresse hídrico). O Si depositase em nível de parede celular conferindo maior consistência, aumenta a elasticidade e pode até estimular os mecanismos de defesa da planta (MA; MIYAKE; TAKAHASHI, 2001).
O Si apresentou eficácia também na prevenção da rachadura ('cracking') em frutos de cereja. Os resultados obtidos em diversos ambientes e distintas cultivares (Tabela 7) demonstraram que pulverizações de Si na copa são capazes de reduzir sensivelmente a rachadura dos frutos de cereja, em medida análoga ou superior ao cloreto de cálcio (SORRENTI et al., 2008a). As fontes de Si utilizadas em agricultura são diversas: silicato de potássio $\left(25 \%\right.$ de $\left.\mathrm{SiO}_{2}\right)$, silicato de cálcio (mais de $15 \%$ de $\mathrm{SiO}_{2}$ ), gel de sílica, palha de arroz, pula de arroz (com mais de $20 \%$ de $\mathrm{SiO}_{2}$ ), equiseto e outras.

Tabela 7. Efeito de tratamentos foliares sobre a incidência percentual de frutos rachados da cerejeira (cv New Star), Modena, Itália, junho 2007.

\begin{tabular}{lc}
\hline \multicolumn{1}{c}{ Tratamento $^{1}$} & Incidência de rachadura nos frutos (\%) \\
\hline Controle (água) & $58 \mathrm{a}$ \\
Cloreto de cálcio $(0,5 \%)$ & $64 \mathrm{a}$ \\
Silicato de sódio $\left(2,3 \% ; 36-40^{\circ}\right.$ Bé) & $41 \mathrm{~b}$ \\
\hline Significância & $* * 2$ \\
\hline
\end{tabular}

${ }^{1} \mathrm{O} \mathrm{pH}$ das soluções utilizadas nos tratamentos foi ajustado a $5,5 \mathrm{com} \mathrm{HCl}$

$2 * *$ : significativo para $\mathrm{P} \leq 0,01$

Fonte: Sorrenti et al. (2008a).

\section{Análise foliar}

As técnicas de avaliação do estado nutricional, em particular a diagnose foliar, representam instrumentos essenciais para verificar a necessidade dos interventos de fertilização. A composição mineral da folha é condicionada por diversos fatores, entre os quais, os mais importantes são: o genótipo (espécie, cultivar e porta-enxerto), a idade da folha e a carga produtiva da planta, o ambiente pedoclimático e as técnicas culturais aplicadas.

A utilidade da diagnose foliar depende da disponibilidade de valores padrões confiáveis obtidos em nível local, capazes de representar as características peculiares pedoclimáticas. A maior parte dos padrões para a interpretação da diagnose foliar se refere a medidas realizadas no verão, quando a concentração dos nutrientes é estável e o confronto entre diversas amostras é menos influenciado pela variabilidade causada pela idade da folha.

Com o objetivo de poder corrigir imediatamente eventuais carências nutricionais é necessário dispor de índices foliares padrões muito precocemente.

Juntamente com as análises foliares de rotina, pode ser oportuno, nos solos sujeitos a potenciais carências (solos ácidos), determinar a cada 3 ou 4 anos a concentração do molibdênio foliar, pois tal elemento é componente essencial da enzima nitrato-redutase e, portanto, adequados níveis $(0,2$ ppm na folha) são importantes para a conversão e assimilação do nitrato. 
A respeito dos níveis foliares de ferro, em consequência fenômenos de inativação fisiológica nos tecidos foliares, a concentração de ferro total não reflete uma efetiva disponibilidade do micronutriente (RöMHELD, 2000) .

\section{Considerações finais}

Os atuais conhecimentos sobre a fisiologia da nutrição nos permitem ter a disposição os nutrientes necessários para a fertilização das drupáceas em vários ambientes e tipologias de pomares. O manejo adequado da fertilização deve proporcionar produções compatíveis, frutas de alta qualidade em função da destinação final do fruto e total respeito ao ambiente. Particular atenção à manutenção e/ou incremento do conteúdo de matéria orgânica, a qual garante uma elevada fertilidade do solo, facilita o manejo da nutrição, sem o risco de causar carências ou desequilíbrios que podem prejudicar a qualidade dos frutos e o êxito produtivo. A técnica de cobertura vegetal do solo pode contribuir para aumentar o conteúdo de matéria orgânica e incrementar a disponibilidade de nutrientes no solo.

A nova fronteira da fertilização é representada pela avaliação agronômica de estratégias capazes de induzir uma menor suscetibilidade aos estresses ambientais (estresses térmicos, hídricos e nutricionais) e aos patógenos, melhorando os componentes qualitativos dos frutos.

\section{Referências}

ALCARAZ-LOPEZ, C.; BOTIA, M.; ALCARAZ, C. F. Effects of foliar sprays containing calcium, magnesium and titanium on plum (Prunus domestica L.) fruit quality. Journal of Plant Physiology, Waterbury, v. 160, n. 12, p. 1441-1446, 2003.

AMADEI, P.; QUARTIERI, M.; PELLICONI, F.; SCUDELLARI, D.; COLOMBO, R.; INNOCENTI, A.; TAGLIAVINI, M. Confronto tra dosi e modalità di distribuizione dei nutrienti nella concimazione del pescheto. Italus Hortus, Firenze, v. 13, n. 3, p. 109-112, 2006.
BALDI, E. Efficienza e dinamica dello sviluppo dell'apparato radicale in piante di pesco concimate con sostanza organica. 2006. Tesi (Dottorato em Frutticoltura) - Dipartimento di Colture Arboree. Università di Bologna, Bologna.

BALDI, E.; TOSELLI, M.; MARCOLINI, G.; QUARTIERI, M.; CIRILO, E.; INNOCENTI, A.; MARANGONI, B. Compost can successfully replace mineral fertilizers in the nutrient management of commercial peach orchard. Soil use and Management, Stirling, v. 26, n. 3, p. 346-353, 2010.

BROWN, P. H.; HU, H.; ROBERTS, W. G. Occurrence of sugar alcohols determines boron toxicity symptoms of ornamental species. Journal of the American Society for Horticultural Science, Geneva, v. 124, n. 4, p. 347-352, 1999.

CALLAN, N. W.; THOMPSON, M. M.; CHAPLIN, M. H.; STEBBINS, R. L.; WESTWOOD, M. N. Fruit set of Italian prune following fall and spring B sprays. Journal of the American Society for Horticultural Science, Geneva, v. 103, n. 2, p. 253-257, 1978.

CAO, T.; DUNCAN, R. A.; MCKENRY, M. V.; KENNETH, A.; SHACKEL, T.; DEJONG, M.; KIRKPATRICK, B. C. Interaction between nitrogenfertilized peach trees and expression of syrB, a gene involved in syringomycin production in Pseudomonas syringae pv. Syringae. Journal of Bacteriology, Washington, v. 95, n. 5, p. 581-586, 2005.

CARNEVALI, G.; DRAHORAD, W.; FERALLI, S.; FORNACIARI, M.; GUARINO, F.; LACERTOSA, G.; MATTATELLI, B.; MENNONE, C.; PANTEZZI, T.; PELLICONI, F.; SARNO, G.; SCUDELLARI, D. Aspetti tecnici e normativi della fertilizzazione delle colture frutticole in Italia. Italus Hortus, Firenze, v. 13, n. 3, p. 46-59, 2006.

CESCO, S.; ROMBOLÀ, A. D. Nutrient management at the rhizosphere through intercropping. In: GOODMAN, R. M. (Ed.). ENCYCLOPEDIA of plant and crop science. London, UK: Ed. Taylor and Francis, 2007. p. 1-3.

DAY, K. R.; JOHNSON, S. R.; CRISOSTO, C.; DEJONG, T.; SEARCY, S.; ALLEN, B. Plum nutrition studies. 1999. CTFA Research Report. Disponível em: $<\mathrm{http} / / /$ cetulare.ucdavis.edu/pubfruit/plum.pdf $>$. Acesso em: 01 set. 2011.

FURUYA, S.; UMEMIYA, Y. The influence of chemical forms on foliar applied nitrogen absorption for peach trees. Acta Horticulturae, Wageningen, n. 594, p. 97-103, 2002 . 
GAO, Y. P.; MOTOSUGI, A.; SUGIURA, A. Rootstock effect on growth and flowering in young apple trees grown with ammonium and nitrate nitrogen. Journal of the American Society for Horticultural Science, Geneva, v. 117, n. 3, p. 446-452, 1992.

GIOVANNINI, D.; MERLI, M.; MARANGONI, B. Gestione integrata e convenzionale del pescheto: influenza sulle caratteristiche vegeto-produttive degli alberi e sulla fertilità del terreno. Frutticoltura, Bologna, v. 65 , n. 7-8, p. 39-48, 2003.

JOHNSON, R. S.; URIU, K. Mineral nutrition. In: LARUE, J. H.; JOHNSON, R. S. (Ed.). PEACHES, plums, and nectarines, growing and handling for fresh market. [California]: University of California, Division of agriculture and Natural Resources, 1989. p. 68-81 (Publication, n. 3331).

JOHNSON, R. S.; AMDRIS, H. Combining low biuret urea with foliar zinc sulphate sprays to fertilize peach and nectarine trees in the fall. Acta Horticulturae, Wageningen, n. 564, p. 321-327, 2001.

JOHNSON, R. S.; ROSECRANCE, R.; WEINBAUM, S.; ANDRIS, H.; WANG, J. Can we approach complete dependence on foliar-applied urea nitrogen in an early maturing peach? Journal of the American Society for Horticultural Science, Geneva, v. 126, n. 3, p. 364-370, 2001.

KIRAN, U.; PATRA, D. D. Influence of natural essential oils and their by-products as nitrification retarders in regulating nitrogen utilization for Japanese mint in sandy loam soils of subtropical central India. Agriculture, Ecosystem and Environment, Zurich, v. 94, n. 2, p. 237$245,2003$.

LOBIT, P.; SOING, P.; GENARD, M.; HABIB, R. Effect of timing of nitrogen fertilization on shoot development in peach (Prunus persica) trees. Tree Physiology, Oxford, v. 21, n. 1, p. 35-42, 2001.

MA, J. F.; MIYAKE, Y.; TAKAHASHI, E. Silicon as a beneficial element for crop plants. In: (DATNOFF, L. E.; SNYDER, G. H.; KORNDORFER, G. H. (Ed.). $V$ SILICON in agriculture. [S.1.]: Elsevier Science, 2001. cap. 2, p. 17-39.

MALAGUTI, D.; ROMBOLÀ, A. D.; QUARTIERI, M.; LUCCHI, A. Effects of the rate of nutrients by fertigation and broadcast application in "Gala" and "Fuji" apple. Acta Horticulturae, Wageningen, n. 721, p. 165-171, 2006.

MARANGONI, B.; QUARTIERI, M.; SCUDELLARI, D. Gestione del suolo, irrigazione e fertilizzazione del ciliegio. L'Informatore Agrario, Verona, n. 27, p. 45-53, 1998.
MARSCHNER, H. Mineral nutrition of higher plants. London : Academic Press, 1995. 889 p.

MATOCHA, J. E.; PENNINGTON, D. Effects of plant iron recycling on iron chlorosis of grain sorghum on calcareous soils. Journal of Plant Nutrition, New York, v. 5, n. 4-7, p. 869-882, 1982.

MUÑOZ, N.; GUERRI, J.; LEGAZ, F.; PRIMO-MILLO, E. Seasonal uptake of ${ }^{15} \mathrm{~N}$ nitrate and distribution of absorbed nitrogen in peach trees. Plant and Soil, Crawley, v. 150, n. 2, p. 263-269, 1993.

NEILSEN, G. H.; HOYT, P. B.; NEILSEN, D. Soil chemical changes associated with NP-fertigated and drip irrigated high-density apple orchards. Canadian Journal of Soil Science, Ottawa, v. 75, n. 3, p. 307-310, 1995.

NEUMANN, G.; KOHLS, S.; LANDSBERG, E.; STOCK-OLIVEIRA SOUZA, K.; YAMADA, T.; RÖMHELD, V. Relevance of glyphosate transfer to non-target plants via the rhizosphere. Journal of Plant Diseases and Protection, Pretoria, n. 20, p. 963-969, 2006. Special Issue.

QUARTIERI, M.; TAGLIAVINI, M.; MARANGONI, B.; CONCARI, G.; MALAGUTI, D.; MILLARD, P. Il ciclo interno dell'azoto negli alberi di pesco. Frutticoltura, Bologna, v. 61, n. 2, p. 61-66, 1999.

PLICH, H. E.; WOJCIK, P. The effect of calcium and boron foliar application on postharvest plum fruit quality. Acta Horticulturae, Wageningen, n. 594, p. 445-451, 2002.

ROMBOLÀ, A. D.; QUARTIERI, M.; TAGLIAVINI, M.; IANNONE, C.; ZAVALLONI, C.; MARANGONI, B. Fertilizzazione azotata nel pescheto attraverso l'impiego di formulati a lento rilascio ed irrorazioni fogliari. In: CONVEGNO PESCHICOLO, 22., 1995, Cesena. Atti... Cesena: Camera di commercio industria e artigianato e agricoltura di Cesena, 1997. p. 195-201.

ROMBOLÀ, A. D.; ZAVALLONI, C.; SCUDELLARI, D.; CECCAROLI, A.; MAZZANTI, F.; MARANGONI, B.; TAGLIAVINI, M. La fertirrigazione del meleto nella fase d'allevamento: effetti della dose e del tipo di nutrienti. Frutticoltura, Bologna, v. 62, n. 5, p. 67-74, 2000 a.

ROMBOLÀ, A. D.; TOSELLI, M.; SCUDELLARI, D.; TAGLIAVINI, M.; MARANGONI, B. A nutrição das fruteiras de caroço na fruticultura eco-compatível. In: SIMPOSIO INTERNACIONAL DE FRUTAS DE CAROÇO, 1., 2000, Porto Alegre. Anais... Porto Alegre: UFRGS, 2000b. p. 16-18. 
ROMBOLÀ, A. D.; MAZZANTI, F.; SORRENTI, G.; MARANGONI, B. Plant water extracts: a new strategy to overcome $\mathrm{Fe}$ chlorosis in fruit trees. In: INTERNATIONAL HORTICULTURAL CONGRESS \& EXHIBITION, 26., 2002, Toronto. Abstracts... Toronto: ISHS, 2002. p. 287.

ROMBOLÀ, A. D.; BALDI, E.; FRANCESCHI, A.; AMMARI T.; MINGUEZ PARAMIO, J.; TAGLIAVINI, M. Prevenzione della clorosi ferrica dell'actinidia (Actinidia deliciosa) mediante consorciazione temporanea con specie graminacee. In: CONVEGNO NAZIONALE ACTINIDIA: LA NOVITÀ FRUTTICOLA DEL SECOLO, 20., 2003, Verona. Atti... Verona: Camera di Commercio industria e artigianato di Verona, 2003. p. 249-254.

RöMHELD, V. The chlorosis paradox: Fe inactivation as a secondary event in chlorotic leaves of grapevine. Journal of Plant Nutrition, Phyladelphya, v. 23, n. 11-12, p. 1629-1643, 2000.

ROSECRANCE, R. C.; JOHNSON, R. S.; WEINBAUM, S. A. The effect of timing of post-harvest foliar urea sprays on nitrogen absorption and partitioning in peach and nectarine trees. Journal of Horticultural Science \& Biotechnology, Ashford, v. 73, n. 6, p. 856-861, 1998.

ROVERSI, A.; MONTEFORTE, A. Effetti di diverse tecniche di gestione del suolo nel ceraseto. Frutticoltura, Bologna, v. 65, n. 6, p. 55-58, 2003.

SANCHEZ, E. E.; WEINBAUM, S. A.; JOHNSON, R. S. Comparative movement of labelled nitrogen and zinc in 1-year-old peach (Prunus persica (L.) Batsch) trees following late-season foliar application. Journal of Horticultural Science Biotechnology, Ashford, v. 81, n. 5, p. 839-844, 2006.

SCUDELLARI, D.; TAGLIAVINI, M.; MARANGONI, B.; RUBBI, L.; CAPUCCI, V.; PELLICONI, F. Approccio integrato della concimazione azotata del frutteto. Notiziario Tecnico CRPV , n. 54, p. 20-28, 1998a.

SCUDELLARI, D.; SPADA, G. L.; ZAVALLONI, C.; MARANGONI, B.; MAZZANTI, F.; MIGNANI, I. Influenza dei trattamenti di calcio alla chioma sulla qualità dei frutti di pesco (cv 'Caldesi 84'). Notiziario Tecnico CRPV, Cesena, n. 54, p. 29-34, 1998b.

SHU, Z. H.; OBERLY, G. H.; CARY, E. E.; RUTZKE, M. Absorption and translocation of boron applied to aerial tissue of fruiting "Reliance" peach trees. HortScience, Washington, v. 1, n. 29, p. 25-27, 1994.

SORRENTI, G.; QUARTIERI, M.; CARUSO, S.; LUGLI, S.; ROMBOLÁ, A. D.; MARANGONI, B. Efficace l'impiego di silicato di sodio e cloruro di calcio per ridurre lo spacco dei frutti di ciliegio (Prunus avium L.) Frutticoltura, Bologna, v. 70, n. 3, p. 8-12, 2008 a.

SORRENTI, G.; FACHINELLO, J. C.; CASTILHOS, D. D.; BIANCHI, V. J.; MARANGONI, B. Efeito da fertilizaçao organica no crescimento de plantas de tangerineira (cv. Clemenules) e nos atributos quimicos e microbiologicos do solo. Revista Brasileira de Fruticultura, Jaboticabal, v. 30, n. 4, p. 1129-1135, 2008b.

SORRENTI, G.; BALDI, E.; TOSELLI, M.; MARANGONI, B. Con gli estratti vegetali il pero si sviluppa meglio. Agricoltura, Bologna, n. 10, p. 91-93, 2009.

SOTIROPOULOS, T.; THEORIOS, I.; VOULGARAKIS, $\mathrm{N}$. Effect of various foliar sprays on some fruit quality attributes and leaf nutritional status of the peach cultivar 'andross'. Journal of Plant Nutrition, Phyladelphya, v. 33, n. 4, p. 471-484, 2010.

TAGLIAVINI, M.; SCUDELLARI, D.; MARANGONI, B.; TOSELLI, M. Nuovi aspetti della fertilizzazione azotata nel frutteto. Frutticoltura, Bologna, v. 57, n. 3, p. 37-44, 1995.

TAGLIAVINI, M.; MILLARD, P.; QUARTIERI, M.; MARANGONI, B. Storage of foliar absorbed N and remobilisation for spring growth in young nectarine (Prunus persica var. nectarina) trees. Tree Physiology, Oxford, v. 18, n. 3, p. 203-207, 1998.

TAGLIAVINI, M.; NEILSEN, G. H.; ROMBOLÁ, A. D.; ZAVALLONI, C.; MALAGUTI, D.; MARANGONI, B.; SCUDELLARI, D. Influenza della temperatura del terreno sulla risposta del pesco alla fertilizzazione fosfatica. In: CONVEGNO PESCHICOLO, 23., 2000, Ravenna. Atti... Ravenna: Camera di commercio industria e artigianato e agricoltura di Ravenna e Forlì-Cesena, 2000a. p. 124-126.

TAGLIAVINI, M.; QUARTIERI, M.; ROMBOLÁ, A. D.; ZAVALLONI, C.; MALAGUTI, D.; MARANGONI, B.; SCUDELLARI, D. Ripartizione degli elementi minerali nei frutti degli alberi decidui. Frutticoltura, Bologna, v. 62, n. 1, p. 83-87, 2000b.

TAGLIAVINI, M.; TONON, G.; SCANDELLARI, F.; QUIÑONES, A.; PALMIERI, S.; MENARBIN, G.; GIOACCHINI, P.; MASIA, A. Nutrient recycling during the decomposition of apple leaves (Malus domestica) and mowed grasses in an orchard. Agriculture, Ecosystems and Environment, New York, v. 118, n. 1-4, p. 191-200, 2007.

TOSELLI, M.; TITTARELLI, F.; MARANGONI, B. La fertilizzazione del pescheto nella frutticoltura moderna. L'Informatore agrario, Verona, n. 46, p. 55-59, 1999. 
TOSELLI, M.; MARANGONI, B.; TAGLIAVINI, M.; SCUDELLARI, D.; ROMBOLA, A. D.; QUARTIERI, M.; BALDI, E.; MALAGUTI, D.; SORRENTI, G.; MARCOLINI, G. La fertilizzazione delle drupacee. Notiziario tecnico, CRPV, Cesena, n. 74, p. 64, 2006.

USENIK, V.; STAMPAR, F. Effect of foliar application of zinc plus boron on sweet cherry fruit set and yield. Acta Horticulturae, Wageningen, n. 594, p. 245-249, 2002.

WEINBAUM, S. A.; BROWN, P. H.; JOHNSON, R. S. Application of selected macronutrients $(\mathrm{N}$ e $\mathrm{K})$ in deciduous orchards: physiological and agro technical perspectives. Acta Horticulturae, Wageningen, n. 594, p. 59-64, 2002.

XILOYANNIS, C.; CELANO, G.; NUZZO, V. Domanda annuale di elementi minerali in specie arboree da frutto in ambiente mediterraneo. Italus Hortus, Firenze, v. 13, n. 3, p. 30-34, 2006.
ZAPPIA, R.; COSTANZO, A.; DATTOLA, A.; MAFRICA, R. Influenza della forma chimica e della quantità di azoto sul comportamento vegeto-produttivo di piante di lampone (cv Tulameen) allevate in contenitore. Italus Hortus, Firenze, v. 13, n. 3, p. 96-99, 2006.

ZAVALLONI, C.; ROMBOLÀ, A. D.; BELLETTI, M.; PELLICONI, F.; TAGLIAVINI, M. Nutrizione del pesco: una tecnica innovativa. Supplemento a Terra e Vita, Bologna, n. 13, p. 8-11, 1998.

ZHANG, Q.; BROWN, P. H. Distribution and transport of foliar applied zinc in pistachio. Journal of the American Society for Horticultural Science, Geneva, v. 124, n. 4, p. 433-436, 1999. 